\title{
Alcohol and Fetoplacental Vasoconstrictor Reactivity
}

\author{
V. JAKOUBEK ${ }^{1}$, V. HAMPL ${ }^{1}$ \\ ${ }^{1}$ Department of Physiology, Second Medical School, Charles University, Prague, Czech Republic
}

Received February 3, 2017

Accepted December 15, 2017

On-line March 12, 2018

\begin{abstract}
Summary
Alcohol abuse during pregnancy is a well-known factor in fetal morbidity, including smaller fetal size. We have shown that chronic hypoxia, considered the main pathogenetic factor in intrauterine growth restriction, elevates fetoplacental vascular resistance (and vasoconstrictor reactivity) and thus, presumably, reduces placental blood flow. We thus hypothesized that alcohol may affect the fetus - in addition to other mechanisms - by altering fetoplacental vascular resistance and/or reactivity. Using isolated, double-perfused rat placenta model, we found that maternal alcohol intake in the last third of gestation doubled the vasoconstrictor responses to angiotensin II but did not affect resting vascular resistance. Reactivity to acute hypoxic challenges was unchanged. Chronic maternal alcohol intake in a rat model alters fetoplacental vasculature reactivity; nevertheless, these changes do not appear as serious as other detrimental effects of alcohol on the fetus.
\end{abstract}

\section{Key words}

Ethanol • Intrauterine growth restriction • Placenta • Vascular reactivity • Angiotensin II

\section{Corresponding author}

V. Hampl, Department of Physiology Second Medical School, Charles University in Prague, V Úvalu 84, 15000 Prague 5 Motol, Czech Republic. E-mail: vaclav.hampl@If2.cuni.cz

\section{Introduction}

Chronic alcohol intake by the mother during pregnancy is all too well known to seriously harm the fetus. While the worst aspect of this problem is the ethanol-induced damage to the developing brain, the impairment of fetal growth is also a well established feature of fetal alcohol syndrome (Carter et al. 2007, Day et al. 1990, Gundogan et al. 2008). The reduced body size persists long beyond neonatal age (Day et al. 1994), and is also associated with increased incidence of a number of health problems in adulthood, including cardiovascular diseases, obesity, metabolic syndrome and type II diabetes (Briana et al. 2009, Demicheva et al. 2014, Ross et al. 2008, Simmons et al. 2001). Therefore, understanding the mechanisms of intrauterine growth restriction (IUGR) in children of alcohol-abusing mothers seems important for possible mitigation of life-long consequences for these children.

Alcohol can affect fetal growth through its oxidant properties (Bondy 1992). Inasmuch as alcohol is a well-known vasoactive agent, it is possible that it might influence fetoplacental blood flow. Reductions in this parameter are recognized as causative in IUGR (Browne et al. 2015, Hampl et al. 2009, Krishna et al. 2011). Diminished blood flow through the placenta reduces nutrient and oxygen supply to the fetus and thus reduces its growth (Fowden et al. 2006, Reynolds et al. 2006).

We have shown that another external influence known to induce IUGR, chronic hypoxia, increases fetoplacental vascular resistance and vasoconstrictor reactivity (Jakoubek et al. 2008). Since both maternal hypoxia and alcohol drinking induce IUGR, we hypothesized that maternal alcohol intake has similar effects on the fetoplacental vasculature as chronic hypoxia, i.e. increased resistance and reactivity that could provide a plausible mechanism for the development of IUGR. To test this hypothesis, we measured fetoplacental vascular resistance and vasoconstrictor responses in rats 
given ethanol in the last third of gravidity.

Methodologically, the study used the isolated, doubly perfused rat placenta model (Jakoubek et al. 2008). All procedures conformed to the European Union regulations for experimental animal care and were approved by the ethical committee of our institution. Pregnant Wistar rats (Biotest, Konárovice, Czech Republic, $\mathrm{n}=7$ ) were given $5 \%$ ethanol in their drinking water (Wilcoxon et al. 2003) during days 14-20 of gestation (term $=21$ days). The average consumption of this solution was $306 \pm 29 \mathrm{ml} / \mathrm{d}$. The control group (no alcohol, $\mathrm{n}=8$ ) was the same as in the study published earlier (Jakoubek et al. 2008). Both studies were performed at the same time (May 2006).

One day before the expected date of delivery, the isolated, dually perfused placenta was prepared under thiopental anesthesia $(50 \mathrm{mg} / \mathrm{kg}$ i.p.) as previously described (Jakoubek et al. 2008) and perfused at $1 \mathrm{ml} / \mathrm{min}$ with Krebs solution $\left(37^{\circ} \mathrm{C}\right.$ ) (all chemicals were from Sigma, Prague, Czech Republic) equilibrated with an air $+5 \% \mathrm{CO}_{2}$ mixture. One placenta was used from each dam. After $\geq 15$ min of stabilization, three increasing doses of angiotensin II $(0.1,0.15$, and $0.2 \mu \mathrm{g})$ were injected into the fetal arterial cannula at 10-min intervals. Acute hypoxic vasoconstriction was then elicited by switching the bubbling of the perfusate to a $5 \% \mathrm{CO}_{2}+$ $95 \% \mathrm{~N}_{2}$ mixture for $10-15 \mathrm{~min}$. The same acute hypoxic challenge was repeated after a 15 -min normoxic interval.

The data were evaluated statistically using StatView 5.0.1 software (SAS Institute, Cary, NC, USA) and are presented as means \pm SEM. Reactivity data were compared between groups using repeated-measures ANOVA. An unpaired $t$-test was used for simple comparisons between the groups (maternal body weight, etc.). Differences were regarded as significant at $\mathrm{P}<0.05$.

Our results show a statistically non-significant tendency for alcohol drinking dams to be lighter than controls ( $365 \pm 15$ vs. $431 \pm 30 \mathrm{~g}, \mathrm{P}=0.063)$. The same was true for the weight of the fetuses ( $3.6 \pm 0.4$ vs. $4.0 \pm 0.3 \mathrm{~g}$, $\mathrm{P}=0.46)$ and placentae $(0.51 \pm 0.05$ vs. $0.60 \pm 0.05 \mathrm{~g}$, $\mathrm{P}=0.25$ ). Consequently, there were no significant differences between the groups in the ratio of placenta weight relative to maternal weight $(0.14 \pm 0.02$ vs. $0.14 \pm 0.01 \%)$ and in the fetal to maternal weight ratio $(0.98 \pm 0.08$ vs. $0.96 \pm 0.10 \%)$. Only the placenta used for perfusion and its fetus were weighed from each dam. There was no difference in litter size between the groups (11.0 0.4 vs. $11.4 \pm 0.4)$.

After initiation of artificial perfusion, there was no difference between the baseline fetoplacental perfusion pressures of the control and alcohol-exposed groups $(34.2 \pm 1.9$ vs. $32.0 \pm 1.8 \mathrm{~mm} \mathrm{Hg}, \mathrm{P}=0.42)$. After each vasoconstrictor challenge (with angiotensin II or acute hypoxia), the fetoplacental perfusion pressure returned to almost the same level as was before the challenge. There were no significant differences in this behavior between the groups. Consequently, the baseline fetoplacental pressure did not differ between the groups throughout the experiment (Fig. 1).

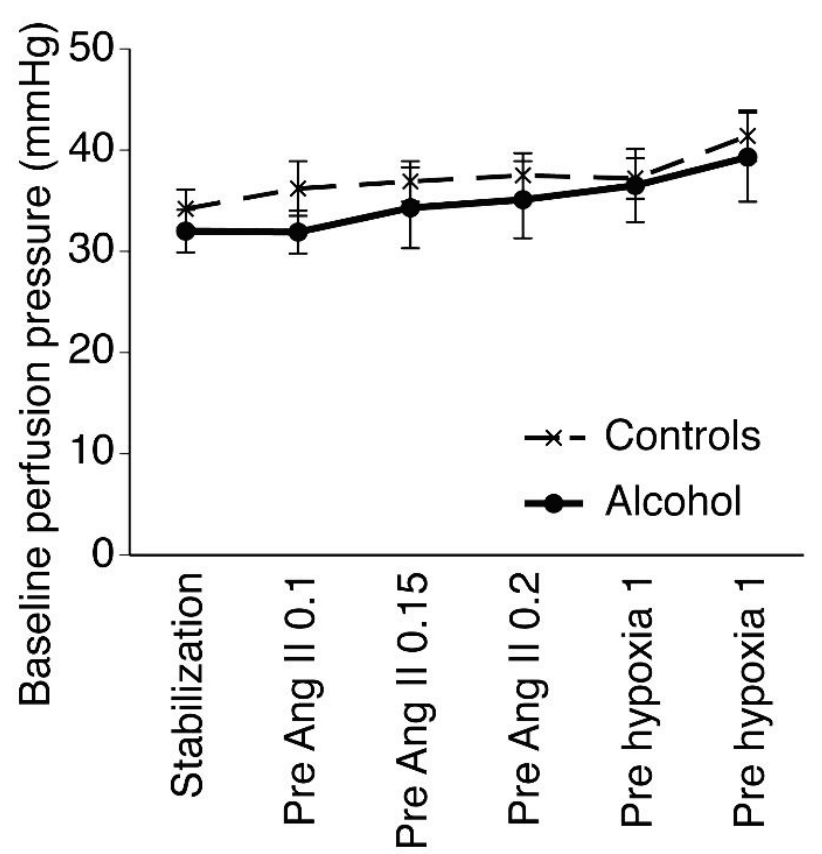

Fig. 1. Baseline perfusion pressure in the isolated rat placenta is not affected by chronic maternal alcohol intake. Mean values ( \pm SEM) before individual angiotensin (Ang) II injections and hypoxic challenges are shown. $n=8$ in the control group and 7 in the alcohol group.

Injections of angiotensin II boluses elicited rapid (within seconds), sharp peaks in perfusion pressure that quickly returned to the base-line level. The magnitudes of the peaks were significantly higher in the alcoholexposed placentae than in controls (Fig. 2A) and were not dose-dependent in the selected range of doses. By contrast, acute hypoxic challenges elicited relatively slow (within minutes) increases of perfusion pressure to a plateau that remained stable for the duration of the challenge and then returned close to baseline. The heights of the plateaus of the responses to acute hypoxia did not differ between the two groups (Fig. 2B). The magnitude of the vasoconstrictor response to hypoxic stimuli did not change with repetition, and this was so for both groups. 

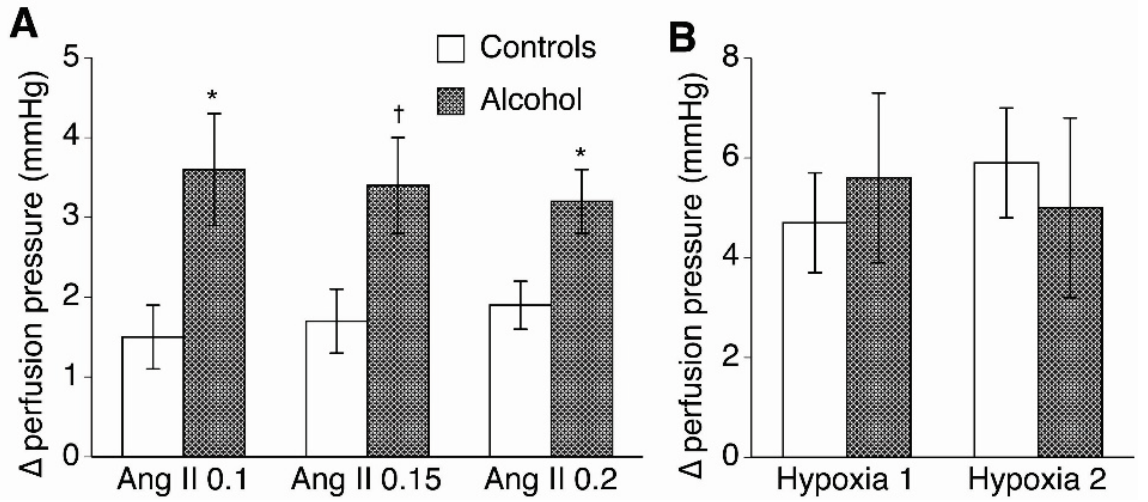

Fig. 2. Fetoplacental vasoconstrictor responses to angiotensin II (Ang II; A), but not acute hypoxia (B) are markedly augmented by chronic maternal alcohol intake. Hypoxia 1 and Hypoxia 2 in panel B represent two repetitions of an identical hypoxic stimulus. Data are means \pm SEM. $n=8$ in the control group and 7 in the alcohol group. $* \mathrm{P}<0.05$ Controls vs. Alcohol, ${ }^{\dagger} \mathrm{P}<0.01$ Controls vs. Alcohol.

The main findings of our study are that in rats, maternal alcohol intake in the last third of pregnancy does not alter baseline fetoplacental vascular resistance, but does increase fetoplacental vasoconstrictor responses to some (angiotensin II), but not all (acute hypoxia) vasoconstrictor stimuli. Contrary to our hypothesis, the normal baseline fetoplacental vascular resistance after chronic alcohol intake suggests that alteration of fetoplacental vessels is not a major contributor to IUGR in offspring of alcohol-abusing dams. Nevertheless, the increased vasoconstrictor responses to at least some stimuli suggest that under conditions of hormonal perturbation (such as renin-angiotensin axis activation) reduced fetoplacental perfusion might contribute to IUGR.

It is intriguing that the responses to angiotensin II were increased in the placentae of dams with elevated alcohol consumption. Maternal plasma angiotensin II levels are markedly increased in pregnancy, especially in its later phases (Anton et al. 2008). There is ample evidence of an association between angiotensin II, alcohol abuse and its effects in the organism. Alcohol consumption appears controlled by angiotensin II (Maul et al. 2005, Maul et al. 2001). At least some of the adverse effects of alcohol abuse are mediated by angiotensin II and its receptors (Cheng et al. 2006, Tan et al. 2012, Uesugi et al. 2004). Our data suggest that the adverse effect of maternal alcohol abuse on fetal size might, to some extent, also be mediated by angiotensin II. This possibility might be worthy of future exploration, as angiotensin II activity is relatively easily manageable by pharmacological tools, thereby offering a chance to positively influence this contributor to fetal alcohol syndrome.

Although in clinical practice alcohol abuse is likely to be a problem for most of the duration of the pregnancy, we chose to study the effects of alcohol intake only in the last third of gravidity [roughly corresponding to the last trimester in humans (De Rijk et al. 2002)]. At that time, the placenta is mostly mature. Therefore, the study does not investigate the effects on alcohol on placental development, but rather on its function once developed. When alcohol is consumed throughout the whole gravidity, it is likely that the effects observed by us will be combined with other effects related to altered placental development in the earlier stages of pregnancy (Coll et al. 2017, Gundogan et al. 2010).

In humans, serious fetal alcohol syndrome appears related to chronic drinking of about 4 standard drinks per day or more (Briggs et al. 2011). For our rats, the only source of fluid was $5 \%$ ethanol solution. Since beer typically contains about $5 \%$ alcohol, our study roughly models the situation of people whose only fluid intake comes from beer. That represents serious alcoholism. In this sense, the dose of alcohol in our study should be sufficient to model a clinically relevant situation in humans. In fact, this dose (even though administered over a longer duration) has been shown previously to have significant effects in pregnant rats (Wilcoxon et al. 2003). Thus, this dose perhaps might be clinically more relevant than higher doses often used in animal studies (e.g. Coll et al. 2017, Perez et al. 2006).

Maternal alcohol consumption leads to oxidative stress and consequently to DNA damage and lipid peroxidation in the placenta (Coll et al. 2017, Gundogan et al. 2010). All these effects could be expected to influence fetoplacental vascular function. However, the present study provides no information about the roles of oxidative stress and its consequences.

Another limitation of this study is the lack of dose dependency of the angiotensin II responses in the range of doses that we used. A likely interpretation is that at these doses we had already reached maximum response. This is rather surprising, because the doses were chosen based on our previous finding that the highest of these doses causes only a moderate 
fetoplacental vasoconstriction (Hampl et al. 2002). In any case, because of this limitation we do not know whether chronic alcohol intake is associated with changes in sensitivity to angiotensin II. The maximum response, however, is clearly increased.

An interesting question for further research is whether the effects of maternal intake (or their absence) are related to the "sex of the placenta" (i.e. of its fetus). Our study was not designed to address this issue, but the evidence is mounting that there is sexual dimorphism in the structure and function of the placenta (reviewed e.g. by Clifton 2010, Rosenfeld 2015). Since gender differences in fetal sensitivity to harmful stimuli have been described (Rosenfeld 2015), it is possible that alcohol consumption altered the proportion of females to males among our placentae, and this could have contributed to the results that we observed.

\section{References}

ANTON L, BROSNIHAN KB: Systemic and uteroplacental renin-angiotensin system in normal and pre-eclamptic pregnancies. Therap Adv Cardiovasc Dis 2: 349-362, 2008.

BONDY SC: Ethanol toxicity and oxidative stress. Toxicol Lett 63: 231-241, 1992.

BRIANA DD, MALAMITSI-PUCHNER A: Intrauterine growth restriction and adult disease: the role of adipocytokines. Eur J Endocrinol 160: 337-347, 2009.

BROWNE VA, JULIAN CG, TOLEDO-JALDIN L, CIOFFI-RAGAN D, VARGAS E, MOORE LG: Uterine artery blood flow, fetal hypoxia and fetal growth. Philos Trans R Soc Lond B Biol Sci 370: 20140068, 2015.

CARTER RC, JACOBSON SW, MOLTENO CD, JACOBSON JL: Fetal alcohol exposure, iron-deficiency anemia, and infant growth. Pediatrics 120: 559-567, 2007.

CHENG CP, CHENG HJ, CUNNINGHAM C, SHIHABI ZK, SANE DC, WANNENBURG T, LITTLE WC: Angiotensin II type 1 receptor blockade prevents alcoholic cardiomyopathy. Circulation 114: 226-236, 2006.

CLIFTON VL: Review: Sex and the human placenta: mediating differential strategies of fetal growth and survival. Placenta 31 (Suppl): S33-S39, 2010.

COLL TA, CHAUFAN G, PEREZ-TITO LG, VENTUREIRA MR, RIOS DE MOLINA MDC, CEBRAL E: Cellular and molecular oxidative stress-related effects in uterine myometrial and trophoblast-decidual tissues after perigestational alcohol intake up to early mouse organogenesis. Mol Cell Biochem 440: 89-104 2018.

DAY NL, RICHARDSON G, ROBLES N, SAMBAMOORTHI U, TAYLOR P, SCHER M, STOFFER D, JASPERSE D, CORNELIUS M: Effect of prenatal alcohol exposure on growth and morphology of offspring at 8 months of age. Pediatrics 85: 748-752, 1990.

DAY NL, RICHARDSON GA, GEVA D, ROBLES N: Alcohol, marijuana, and tobacco: effects of prenatal exposure on offspring growth and morphology at age six. Alcohol Clin Exp Res 18: 786-794, 1994.

DE RIJK EPCT, VAN ESCH E, FLIK G: Pregnancy dating in the rat: placental morphology and maternal blood parameters. Toxicol Pathol 30: 271-282, 2002.

DEMICHEVA E, CRISPI F: Long-term follow-up of intrauterine growth restriction: cardiovascular disorders. Fetal Diagn Ther 36: 143-153, 2014.

FOWDEN AL, GIUSSANI DA, FORHEAD AJ: Intrauterine programming of physiological systems: causes and consequences. Physiology 21: 29-37, 2006.

GUNDOGAN F, ELWOOD G, LONGATO L, TONG M, FEIJOO A, CARLSON RI, WANDS JR, DE LA MONTE SM: Impaired placentation in fetal alcohol syndrome. Placenta 29: 148-157, 2008.

GUNDOGAN F, ELWOOD G, MARK P, FEIJOO A, LONGATO L, TONG M, DE LA MONTE SM: Ethanol-induced oxidative stress and mitochondrial dysfunction in rat placenta: relevance to pregnancy loss. Alcohol Clin Exp Res 34: 415-423, 2010.

HAMPL V, BÍBOVÁ J, STRAŇÁK Z, WU X, MICHELAKIS ED, HASHIMOTO K, ARCHER SL: Hypoxic fetoplacental vasoconstriction in humans is mediated by potassium channel inhibition. Am J Physiol Heart Circ Physiol 283: H2440-H2449, 2002.

HAMPL V, JAKOUBEK V: Regulation of fetoplacental vascular bed by hypoxia. Physiol Res $\mathbf{5 8}$ (Suppl 2): S87-S93, 2009. 
JAKOUBEK V, BÍBOVÁ J, VENCLÍKOVÁ K, TRNKOVÁ A, HERGET J, HAMPL V: Chronic hypoxia increases fetoplacental vascular resistance and vasoconstrictor reactivity in the rat. Am J Physiol Heart Circ Physiol 294: H1638-H1644, 2008.

KRISHNA U, BHALERAO S: Placental insufficiency and fetal growth restriction. J Obstet Gynaecol India 61: 505-511, 2011.

MAUL B, KRAUSE W, PANKOW K, BECKER M, GEMBARDT F, ALENINA N, WALTHER T, BADER M, SIEMS WE: Central angiotensin II controls alcohol consumption via its AT1 receptor. FASEB $J$ 19: 1474-1481, 2005.

MAUL B, SIEMS WE, HOEHE MR, GRECKSCH G, BADER M, WALTHER T: Alcohol consumption is controlled by angiotensin II. FASEB $J$ 15: 1640-1642, 2001.

PEREZ MJ, VELASCO E, MONTE MJ, GONZALEZ-BUITRAGO JM, MARIN JJ: Maternal ethanol consumption during pregnancy enhances bile acid-induced oxidative stress and apoptosis in fetal rat liver. Toxicology 225: 183-194, 2006.

REYNOLDS LP, CATON JS, REDMER DA, GRAZUL-BILSKA AT, VONNAHME KA, BOROWICZ PP, LUTHER JS, WALLACE JM, WU G, SPENCER TE: Evidence for altered placental blood flow and vascularity in compromised pregnancies. J Physiol 572: 51-58, 2006.

ROSENFELD CS: Sex-specific placental responses in fetal development. Endocrinology 156: 3422-3434, 2015.

ROSS MG, BEALL MH: Adult sequelae of intrauterine growth restriction. Semin Perinatol 32: 213-218, 2008.

SIMMONS RA, TEMPLETON LJ, GERTZ SJ: Intrauterine growth retardation leads to the development of type 2 diabetes in the rat. Diabetes 50: 2279-2286, 2001.

TAN Y, LI X, PRABHU SD, BRITTIAN KR, CHEN Q, YIN X, MCCLAIN CJ, ZHOU Z, CAI L: Angiotensin II plays a critical role in alcohol-induced cardiac nitrative damage, cell death, remodeling, and cardiomyopathy in a protein kinase $\mathrm{C} /$ nicotinamide adenine dinucleotide phosphate oxidase-dependent manner. $\mathrm{J} \mathrm{Am} \mathrm{Coll} \mathrm{Cardiol}$ 59: 1477-1486, 2012.

UESUGI T, FROH M, GABELE E, ISAYAMA F, BRADFORD BU, IKAI I, YAMAOKA Y, ARTEEL GE: Contribution of angiotensin II to alcohol-induced pancreatic fibrosis in rats. $J$ Pharmacol Exp Ther 311: 921-928, 2004.

WILCOXON JS, SCHWARTZ J, AIRD F, REDEI EE: Sexually dimorphic effects of maternal alcohol intake and adrenalectomy on left ventricular hypertrophy in rat offspring. Am J Physiol Endocrinol Metab 285: E31-E39, 2003. 